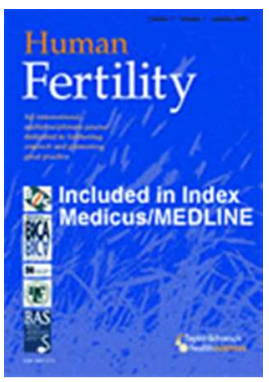

\title{
Deleterious effects of obesity upon the hormonal and molecular mechanisms controlling spermatogenesis and male fertility
}

\begin{tabular}{|r|l|}
\hline Journal: & Human Fertility \\
\hline Manuscript ID: & THUF-2014-0158.R1 \\
\hline Danuscript Type: & Invited Reviews \\
\hline Complete List of Authors: & $\begin{array}{l}\text { Davidson, Lien; University of Oxford, Nuffield Department of Obstetrics and } \\
\text { Gynaecology } \\
\text { Millar, Kate; University of Oxford, Nuffield Department of Obstetrics and } \\
\text { Gynaecology } \\
\text { Jones, Celine; University of Oxford, Nuffield Department of Obstetrics and } \\
\text { Gynaecology } \\
\text { Fatum, Muhammad; University of Oxford, Nuffield Department of } \\
\text { Obstetrics and Gynaecology } \\
\text { Coward, Kevin; University of Oxford, Nuffield Department of Obstetrics and } \\
\text { Gynaecology }\end{array}$ \\
\hline Keywords: & spermatogenesis, obesity, Infertility \\
\hline &
\end{tabular}

SCHOLARONE $^{\text {m }}$

Manuscripts 


\title{
Deleterious effects of obesity upon the hormonal and molecular mechanisms controlling
} spermatogenesis and male fertility

\author{
Lien M. Davidson, Kate Millar, Celine Jones, Muhammad Fatum and Kevin Coward* \\ Nuffield Department of Obstetrics and Gynaecology, University of Oxford, Level 3, Women's \\ Centre, John Radcliffe Hospital, Headington, Oxford, OX3 9DU, UK.
}

\author{
Short title: Obesity and spermatogenesis \\ *Corresponding author \\ Email: kevin.coward@obs-gyn.ox.ac.uk; Telephone: +44 [0] 1864 782878; Fax: +44 [0] \\ 1865769141
}




\section{Abstract}

$2 \quad$ Worldwide obesity rates have nearly doubled since 1980 and currently over $10 \%$ of

3 the population is obese. In 2008, over 1.4 billion adults aged 20 and older were overweight;

4 of these, over 200 million men and nearly 300 million women were obese. While obesity can

5 have many ramifications upon adult life, one growing area of concern is that of reproductive

6 capacity. Obesity affects male infertility by influencing the hypothalamic-pituitary-gonadal

7 axis, thus causing detrimental effects upon spermatogenesis and subsequent fertility. In

8 particular, evidence indicates that excess adipose tissue can alter the relative ratio of

9 testosterone and oestrogen. Additional effects involve the homeostatic disruption of insulin,

10 sex-hormone-binding-globulin, leptin, and inhibin $\mathrm{B}$, leading to diminished testosterone

11 production and impairment to spermatogenesis. Aberrant spermatogenesis arising from

12 obesity is associated with downstream changes in key semen parameters, defective sperm

13 capacitation and binding, and deleterious effects on sperm chromatin structure. More recent

14 investigations into trans-generational epigenetic inheritance further suggest that molecular

15 changes in sperm that arise from obesity-related impaired spermatogenesis, such as modified

16 sperm RNA levels, DNA methylation, protamination, and histone acetylation, can impact

17 upon the development of offspring. Here, we summarise our current understanding of how

18 obesity exerts influence over spermatogenesis and subsequent fertility status, and make

19 recommendations for future investigative research.

20

21 Keywords: Obesity, spermatogenesis, body mass index, infertility, hypothalamic-pituitary-

22 gonadal axis 


\section{Introduction}

25

26

27

28

In 2010, 48.5 million couples globally were affected by infertility (Mascarenhas et al., 2012). Specifically, infertility is estimated to affect one in seven couples in the Western world, with male factor infertility contributing to approximately $40 \%$ of these cases, female factor infertility to $45 \%$, and the remaining proportion due to idiopathic causes (Fritz \& Speroff, 2011). Interestingly, there has been a steady decline in fertility rates over the past 50 years, which has occurred in parallel with an increasing rate of obesity (Hammoud et al., 2012). Obesity is a medical condition where excess body fat has accumulated to an extent where it poses serious health risks, and is determined by body mass index (BMI), a measurement relating weight and height (DuPlessis et al., 2010). According to the National Institutes of Health, individuals with a BMI between 25 and $29.9 \mathrm{~kg} / \mathrm{m}^{2}$ are classified as 'overweight', while those with a BMI greater or equal to $30 \mathrm{~kg} / \mathrm{m}^{2}$ are classified as 'obese' (National Institutes of Health, 1998). Between 1980 and 2008, the worldwide prevalence of obesity nearly doubled, and more than $10 \%$ of the world's adult population is obese (Finucane et al., 2011).

While there has been substantial investigative research targeted to the impact of obesity upon female infertility, specific investigations of the exact relationship between obesity and male factor infertility are relatively rare and tend to be far less conclusive. One study reports that in patients seeking treatment for male infertility, there has been a three-fold increase in the prevalence of obesity (Kasturi et al., 2008). While current data remains highly conflicting, mounting evidence indicates that male obesity is associated with an increased time to conception, reduced pregnancy rates, an an increase in pregnancy loss in couples undergoing assisted reproductive techniques (ART) (Nguyen et al., 2007; RamlauHansen et al., 2007; Hinz et al., 2010; Keltz et al., 2010; Bakos et al., 2011a). 
48 In order to produce healthy fertile sperm from testicular germ cells, the process of 49 spermatogenesis must occur in a normal and natural manner. However, spermatogenesis is a 50 highly complex and specialised process under strict regulatory mechanisms, which involve 51 the hypothalamus, pituitary, Leydig cells, Sertoli cells, and sex steroids (Rawanpura et al., 52 2010). Large amounts of testosterone in the local vicinity, bound by androgen binding 53 protein in the seminiferous tubules, are required to maintain successful spermatogenesis. 54 Normal luteinizing hormone (LH) secretion drives testosterone production by the interstitial 55 Leydig cells, while normal follicle stimulating hormone (FSH) secretion activates Sertoli 56 cells to nourish developing sperm cells throughout the different phases of spermatogenesis.

57 Fluctuations in this specialist environment, particularly with regard to temperature and 58 hormones, have a strong impact upon the process of spermatogenesis. 59 Any disorder affecting gonadotropin releasing hormone (GnRH) secretion from the 60 hypothalamus, or FSH and LH secretion from the pituitary, can impair spermatogenesis and 61 thus fertility (Anawalt, 2013). While the most common cause of male infertility is the 62 idiopathic failure of spermatogenesis, endocrinologists often encounter populations of men 63 with treatable causes of sub-fertility, for example endocrinopathies such as obesity and 64 hyperprolactinaemia (Anawalt, 2013).

65 This review explores how obesity in human males can result in hormonal imbalance 66 with deleterious effects upon sperm formation, how impaired spermatogenesis can affect 67 fertility status, and how paternal obesity at the specific time of conception can influence subsequent health of the offspring.

\section{Obesity can lead to deleterious alterations in important hormonal profiles}

71 One of the most important roles of the hypothalamic-pituitary-gonadal (HPG) axis is 72 in the regulation of reproductive function, and it is widely believed that obesity can lead to 
73 dysregulation of this vital physiological cascade. A bi-directional relationship has been 74 established between hypogonadism and obesity (Rao et al., 2013), largely due to the complex 75 interplay between hypothalamic hormones and the adipocytokines that control the pituitary76 testicular axis. Endocrine changes associated with male obesity can thus result in conditions 77 such as hypogonadotropic hyperoestrogenic hypoandrogenemia, which may adversely affect 78 fertility by reducing testicular function, modifying spermatogenesis, or reducing sexual drive 79 (Reis \& Dias, 2012).

\section{Aromatase over-activity can result in a reduced ratio of testosterone and oestrogen}

Disruption of the HPG axis can result in reduced levels of testosterone and increased levels of oestrogen. These indications have long been associated with sub-fertility and are thus common markers of reproductive health (Handelsman \& Swerdloff, 1985). The HPG axis governs the production of testosterone and is regulated via the direct negative feedback of testosterone upon the hypothalamus. The pulsatile release of GnRH by the hypothalamus

87 drives LH secretion, which ultimately stimulates the testes to produce and secrete testosterone. In adipose tissue, testosterone is metabolised to estradiol by the cytochrome P450 enzyme aromatase, which is responsible for a key step in the biosynthesis of oestrogens and is expressed in higher levels, and with increased activity, in white adipose tissue

91 (Duplessis et al., 2010). The increased bioavailability of aromatase in obese individuals 92 results in the increased conversion of androgens to oestrogens, thereby simultaneously 93 producing increased levels of circulating oestrogen. Increasing BMI has been shown to have 94 a significant association with a reduced testosterone:oestrogen ratio (Hajshafiha et al., 2013).

95 Since oestrogen is more biologically active than testosterone and abnormally high 96 levels of oestrogen can elicit negative feedback upon the HPG axis via kisspeptin neurons 97 (Rao et al., 2013), the high levels of oestrogen in obese males consequently result in a 
98 reduction in testosterone production, subsequently affecting spermatogenesis (Schneider et

99

100

101

102

103

104

105

106

107

108

109

110

111

112

113

114

115

116

117

118

119

120

121 al., 1979; Jensen et al., 2004; Hammoud et al., 2006, 2008; Roth et al., 2008; Chavarro et al., 2010; Macdonald et al., 2010). It has been hypothesized that kisspeptin secretion might be the central pathway linking obesity, testosterone deficiency and environmental factors (Figure 1). Oestrogens further act directly on the testes to regulate their function; different animal models exposed to high levels of oestrogenic chemicals showed a reduction in gonad size and a decrease in sperm count and quality in males (Akingbemi, 2005).

The only somatic cells directly in contact with developing male germ cells are Sertoli cells, which provide nutrients and support. The adhesion of Sertoli cells to the developing germ cells is dependent upon testosterone, with a reduction in testosterone leading to the retention and phagocytosis of mature spermatids (Kerr et al., 1993ab). Furthermore, epithelial function in seminiferous tubules is disrupted by reduced intra-testicular levels of testosterone, thus affecting spermatogenesis (Jensen et al., 2004).

Levels of subcutaneous and visceral fat have both been associated with reduced levels of free testosterone in men (Schneider et al., 1979; Tchernof et al., 1995; Jensen et al., 2004; Winters et al., 2006 Pasquali et al., 2007; Chavarro et al., 2010; Macdonald et al., 2010). Furthermore, adipocytokines (such as the proinflammatory cytokines TNF and IL-6) inhibit the production of testosterone by negatively feeding back to the hypothalamus. Low levels of testosterone have also been shown by CT scanning to correlate with overall obesity, increased waist circumference, and the increased accumulation of visceral fat (Svartberg et al., 2004).

\section{Obesity-related endocrine disruption}

Obesity causes other endocrine changes in the human body, such as changes in the production and regulation of insulin, sex-hormone-binding-globulin (SHBG), leptin, and 
122 inhibin B. Changes in the circulating levels of these hormones impact the 123 testosterone:oestrogen ratio, ultimately impairing spermatogenesis (Figure 2).

124 Testosterone plays a key role in insulin regulation, metabolism of lipids and body 125 composition (Jones, 2010). Hyperinsulinemia has been shown to have an inhibitory effect on 126 spermatogenesis with a significantly higher level of nuclear and mitochondrial DNA damage 127 found in sperm from affected individuals (Agbajes et al., 2007). Increasing BMI and waist 128 circumference is also associated with reduced SHBG levels in the serum (Jensen et al., 2004; 129 Fejes et al., 2005; Winters et al., 2006; Pasquali et al., 2007; Chavarro et al., 2010; Hajshafiha 130 et al., 2013). SHBG is a glycoprotein which binds sex hormones such as testosterone and 131 estradiol in order to inhibit their biological activity. Hyper-insulinemia from obesity-related 132 insulin resistance causes the hepatic production of SHBG to decline, resulting in more 133 biologically active oestrogen to negatively feedback onto the HPG-axis. This fall in SHBG 134 levels may be a homeostatic mechanism to maintain an adequate level of free testosterone, 135 due to the lowered serum levels of testosterone seen in obese males (Chavarro et al., 2010).

136 There is a strong correlation between serum leptin, a hormone secreted by adipocytes, 137 and body fat percentage. Leptin stimulates the satiety center via hypothalamic-mediated 138 effects, but also functions as a metabolic and neuroendocrine hormone in regulating sexual 139 maturation and reproduction, indicating that white adipose can act as an endocrine organ 140 (Jope et al., 2003; Wang et al., 2008; Hofny et al., 2009; Duplessis et al., 2010). Mounting 141 evidence reports a higher prevalence of obesity and high circulating levels of leptin in 142 infertile men (Wang et al., 2008; Duplessis et al., 2010; Farooq et al., 2014). Fat gain due to 143 leptin deficiency caused by the $o b / o b$ gene mutation is well studied, however a majority of 144 obese patients present with elevated serum leptin levels (Considine et al., 1996). Leptin 145 normally stimulates GnRH release, however the excess of leptin associated with obesity 146 causes the HPG axis to become resistant to leptin (Isidori et al., 1999; Rao et al., 2013). Due 
147 to the presence of leptin receptors in testicular tissue, and on the plasma membrane of sperm 148 themselves, it is likely that elevated leptin levels in the serum affect spermatogenesis in obese 149 males. Leptin inhibits stimulation on Leydig cells by the gonadotropins, resulting in a further 150 decline in testosterone production. It has been reported that excess leptin from adipose tissue 151 has deleterious effects upon sperm production and results in increased germ cell apoptosis in 152 testes (Isidori et al., 1999). It is hypothesized that due to the presence of leptin receptors on 153 sperm, leptin might directly affect spermatogenesis via endocrine mechanisms independent of 154 the HPG axis, however the true extent of this theory has yet to be investigated and proven 155 (Jope et al., 2003; Ishikawa et al., 2007).

156 The production of inhibin B by Sertoli cells is the most effective marker for normal 157 spermatogenesis. Inhibin B is a growth-like factor which acts in the testes to inhibit follicle 158 stimulating hormone (FSH) production and to stimulate testosterone production by Leydig 159 cells (Palmer et al., 2012a). The reduced levels of inhibin B found in obese males is 160 indicative of seminiferous tubule dysfunction and is hypothesized to be due to a lower 161 number of Sertoli cells (Jensen et al., 2004; Winters et al., 2006; Aggerholm et al., 2008; 162 Pauli et al., 2008; Macdonald et al., 2010), however a compensatory increase in FSH levels 163 in response to low inhibin $\mathrm{B}$ has not been observed, indicating a potential for partial 164 dysregulation of the HPG axis (Palmer et al., 2012b). These endocrine disruptions caused by 165 obesity ultimately cause further reduction in the levels of testosterone and impair 166 spermatogenesis, thus compromising fertility.

\section{Impaired spermatogenesis affects fertility}

\section{Effects upon traditional WHO semen parameters}

Interestingly, studies investigating how increased BMI might affect routine semen parameters have yielded conflicting results. While it has been reported that obese men are 
172 three times more likely to exhibit a reduction in sperm quality compared to men of normal 173 weight (Sharma et al., 2013; Shulka et al., 2014), the true effect of obesity upon semen 174 quality is a source of much debate. Numerous studies have shown that there is no relationship 175 between increased BMI and one or more of the following semen parameters: sperm 176 concentration, count, morphology, motility, and ejaculate volume (Jensen et al., 2004; Fejes 177 et al., 2006; Aggerholm et al., 2008; Hammoud et al., 2008; Paul et al., 2008; Nicopoulou et 178 al., 2009; Chavarro et al., 2010; Macdonald et al., 2010; Martini et al., 2010; Hajshafiha et 179 al., 2013; Eisenberg et al., 2014). Conversely, other studies show that BMI is associated 180 with one or more of the following: sperm concentration, count, motility, or ejaculate volume 181 (Jensen et al., 2004; Fejes et al., 2006; Hammoud et al., 2006; Kort et al., 2006; Hofny et al., 182 2009; Chavarro et al., 2010; Sermonade et al., 2013; Eisenberg et al., 2014; Hadjkacem et al., 183 2014). The exact cause of poor semen parameters in obese men is difficult to assign due to a 184 paucity of studies specifically investigating treatment of infertility in obese men, conflicting 185 results in the studies that do exist, as well as comorbidities such as cardiovascular disease, (Nguyen et al., 2007). Further conflict could have arisen from the chosen sample populations not being representative of the general population as many studies were carried out in fertility clinics showing bias towards a population of sub-fertile men, from confounding lifestyle 196 factors of impaired sperm function (including smoking, alcohol consumption, recreational 
197 drug use, or co-pathologies), or under-reporting in self-reporting of lifestyle factors and BMI

198 (Palmer et al., 2012).

199 Another important concern to take into account when analysing the effects of male 200 obesity upon semen abnormalities is the potential confounding effect of maternal obesity and 201 whether this leads to semen abnormalities in male offspring. It was hypothesized in 2007 that 202 maternal obesity could have a programming effect upon testicular development in foetal life 203 (Ramlau-Hansen et al., 2007). The authors observed that the sons of mothers who were 204 overweight or obese during pregnancy were more likely to be overweight at birth and exhibit 205 a high BMI in adulthood compared to the sons of normal weighted mothers. It was also 206 suggested that higher free oestrogen levels in mothers (and hence the foetus) could interfere 207 with normal testicular development and future fertility (Ramlau-Hansen et al., 2007). More 208 recently, the same group reported that there was no obvious relationship between high birth 209 weight/prepubertal body fat and semen quality in young adult life, suggesting that the effects 210 of maternal obesity during pregnancy are unlikely to have an effect upon semen quality and 211 subsequent fertility (Ramlau-Hansen et al., 2010).

212 The discrepancies in existing data relating obesity to traditional semen parameters, as

213 well as the confounding variables evident in such studies, have led to the development of 214 rodent models of paternal obesity to help better investigate the effects of obesity on male 215 fertility. It is hoped that such models may, in future, provide a more specific hypothesis.

\section{Deleterious effects upon molecular mechanisms in sperm}

While traditional semen parameters are an important measure for male fertility, it is 219 becoming more apparent that the content and molecular structure of sperm is critical in 220 generating a healthy pregnancy. Male obesity is associated with reduced pregnancy rates and an increase in pregnancy loss in couples undergoing ART (Hinz et al., 2010; Kelts et al., 
2010; Bakos et al., 2011a). Interestingly, one study noted that fertilisation rate was higher among obese men than men of normal weight for conventional IVF cycles, and that there were no significant associations between male BMI and poor quality embryos or cleavage rate (Colaci et al., 2012). However, this same study showed that the odds of live birth in couples with obese male partners undergoing ICSI was $84 \%$ lower than men with normal 227 BMI and concluded there is a possible deleterious effect of male obesity on the odds of 228 having a live birth rate (Colaci et al, 2012). It should be noted however, that if male BMI 229 influences whether patients are treated with ICSI, stratifying data by ICSI may lead to over 230 adjustment bias and thus confound the observed outcomes (Schliep et al., 2015). 231 Conversely, other studies report that for obese patients, rates of fertilisation (Keltz et al., 232 2010) and live birth rates (Peterson, et al. 2013) are reduced following in vitro fertilisation 233 (IVF) but not following ICSI, suggesting impairment in sperm binding. In support of these 234 clinical findings, mouse models of obesity, maintained upon a high fat diet, have shown 235 impaired sperm binding and capacitation compared to healthy controls (Bakos et al., 2011b; 236 Palmer et al., 2012b). A recent study also reported that sustained high protein-tyrosine 237 phosphatase 1B (PTP1B) activity in the sperm of obese mice may represent a vital link 238 between obesity and sub-fertility (Lei et al., 2014). PTP1B is upregulated by pro239 inflammatory factors, such as those released during the chronic inflammatory state of obesity. 240 High levels of PTP1B impairs the reassembly of SNARE proteins causing deleterious effects 241 in the sperm acrosome reaction, and a correlation was identified between high expression and 242 activity of PTP1B and impaired acrosomal exocytosis in sperm. Furthermore, PTP1B is 243 implicated in negative regulation of leptin and insulin signalling (Lei et al., 2014). It should be kept in mind that in many of these studies, the confounding effect of 245 maternal obesity is often not taken into account when associating outcomes to the incidence 246 of male obesity. A recent study reported that weight status (overweight or obese) does not 
247 influence fecundity in couples undergoing infertility treatment. In fact, Schliep et al. (2015)

248 investigated the effects of both male and female body-mass index on pregnancy and birth

249 rates following in vitro fertilisation, and after adjusting for partner BMI, found no significant

250 differences between fertilisation rate, embryo score, pregnancy, or live birth rate compared

251 with normal weight controls.

252

253

Oxidative stress as a causative mechanism of subfertility

254 Obesity causes the body to be in a chronic inflammatory state and it is hypothesized

255 that due to the higher metabolic rates required to maintain normal biological processes, there

256 is an increase in the formation of reactive oxygen species (ROS) which can induce damage to

257 DNA and plasma membrane integrity in sperm, as well as increase stress on the testicular

258 environment (Esposito et al., 2004; Dandona et al., 2005, Agarwal et al., 2006; Duplessis et

259 al., 2010). Studies in humans have shown a positive correlation between levels of BMI and

260 sperm oxidative stress in males (Tunc \& Tremellen, 2011) and rodents (Bakos et al., 2011b),

261 which has further been associated with reduced sperm motility, reduced acrosome reaction

262 and lower embryo implantation rates following IVF (Zorn et al., 2003; Aitkin et al., 2004;

263 Aziz et al., 2004).

264 An excess of scrotal adipose tissue may alter spermatogenesis by increasing testicular 265 temperature or by impacting upon intra-testicular signalling (Cabler et al., 2010).

266 Physiological elevation in scrotal skin temperature has been associated with substantially

267 reduced sperm motility and concentration, concomitant with increased levels of sperm DNA

268 damage and oxidative stress (Paul et al., 2008ab; Shiraishi et al., 2010; Duplessis et al.,

269 2010). Increased apoptosis of spermatozoa is relatively common in obese males since

270 phosphatidylserine externalization is increased and mitochondrial membrane potential is

271 lowered (LaVignera et al., 2012). The potential for impaired acrosome reaction ability and 
272 the conceivable negative effects of obesity-impaired spermatogenesis upon semen parameters

273 via oxidative stress provides a likely explanation for the sub-fertile status of obese men.

274

275 Trans-generational inheritance of obesity

276 It is suggested that paternal obesity at the time of conception can affect the health of 277 resultant offspring. Epidemiology studies have shown that obese fathers have a higher 278 likelihood of fathering obese children (Li et al., 2009), however the individual effects that 279 genetic, epigenetic and environmental factors contribute to this phenomena cannot be readily 280 partitioned for discrete investigation. Therefore, animal models of paternal obesity are being 281 increasingly relied on. There has been recent evidence from such models that paternal 282 obesity compromises both the metabolic and reproductive health of first and second 283 generation offspring (Fullston et al., 2012), as well as influencing the susceptibility of 284 offspring to obesity and diabetes (Mitchell et al., 2010; $\mathrm{Ng}$ et al., 2010). First generation 285 offspring have identified compromised gametes with increased oxidative stress in sperm, 286 changes in the mitochondrial function of oocytes, as well as increased fat mass in females 287 (Fullston et al., 2012). A hypothesis known as 'trans-generational epigenetic inheritance' 288 now purports that molecular changes resulting from impaired spermatogenesis due to obesity, 289 such as changes to DNA methylation, histone acetylation or non-coding RNA levels in 290 sperm, are transmitted to the embryo and consequently affect subsequent development 291 (Youngson \& Whitelaw, 2011; Daxinger et al., 2012; Palmer et al., 2012). This represents an 292 interesting area which needs to be investigated further and could help to develop and improve 293 infertility treatments.

\section{Epigenetic inheritance}

296 DNA methylation is a normal requirement for spermatogenesis. For example, sperm 297 methylation is required for inactivation of the $\mathrm{X}$ chromosome during meiosis and for the 
298 establishment of paternally imprinted genes in sperm (Ooi \& Henikoff, 2007). Analysis of 299 human spermatogenesis indicates the presence of DNA methyltransferase proteins during the 300 spermatogenic cycle, which coincide with the establishment of methylation imprinting in 301 sperm (Jenkins \& Carrell, 2012). Throughout spermatogenesis these imprints are maintained, 302 suggesting they are a key molecular event (Marques et al., 2011). While little is known on 303 the direct impact of obesity on the methylation status of DNA in germ cells, various 304 metabolic disorders, which are commonly associated with obesity, including type 2 diabetes, 305 modify DNA methylation status in somatic tissues, and are thought to have an additional 306 effect on sperm DNA methylation (Barres \& Zierath, 2011). The hypomethylation of repeat 307 elements and imprinted genes have been associated with increased levels of sperm DNA 308 damage and reduced pregnancy rates (Tunc et al., 2009; El Haji et al., 2011; Mino et al., 309 2011; Nanassy \& Carrell, 2011).

310 Histone acetylation is vital for the replacement of histones by protamines, which play 311 a critical role in protecting sperm DNA (Francis et al, 2014), and mouse models maintained 312 upon a high fat diet exhibit alterations in the acetylation of late round spermatids, resulting in 313 increased levels of DNA damage (Gaucher et al., 2010; Palmer et al., 2011). Furthermore, it 314 has been proposed that acetylated histones may have an important effect on embryogenesis 315 via the regulation of gene expression. However, the extent of histone replacement varies 316 widely on a species-specific basis. In human sperm, 15\% of histones remain following 317 protamination, compared to only $1 \%$ in murine models. The retention of a proportion of 318 histones in human sperm is believed to allow pluripotent regulatory genes (such as Nanog, 319 Oct 4, and Sprout) to remain histone-bound with loci capable of somatic cell histone 320 modifications, allowing for their immediate activation and expression post-fertilisation, thus 321 forming the basis for paternal programming in offspring (Farthing 2008). Epigenetic 322 modifications to acetylation of these loci, or to DNA methylation, may therefore differ in the 
323 sperm of obese versus non-obese males, thus affecting subsequent development of the 324 offspring. However, investigative studies of this potential mechanism remain on-going. 325 Furthermore, studies looking into the trans-generational effects of underweight males should 326 also be undertaken to further investigate the trans-generational effects of weight on DNA 327 integrity and sperm RNA levels.

\section{Sperm RNA and obesity}

Mature sperm contain a regulated reserve of mRNA and non-coding RNA thought to

331 be important for successful fertilisation and subsequent embryonic development (Ostermeier 332 et al., 2004; Lalancette et al., 2009; Pradowaka-Dogan et al., 2014). Sperm RNA was 333 originally dismissed as residual from spermatogenesis, however the presence of non coding 334 RNA in sperm of many species targeting a multitude of gene sequences unrelated to 335 spermatogenesis suggests that the sperm RNA is more than just a residual relic and may have 336 post-fertilisation functions including transmission of acquired characteristics (Miller \& 337 Ostermeier, 2013; Sendler et al., 2013; Gapp et al., 2014). It has been demonstrated that 338 offspring show phenotypes of variable severity following inhibition of miRNA in male 339 pronulei of fertilised zygotes depending on the miRNA ratio, indicating these RNAs play a 340 role in oocyte development during fertilisation and early embryo development (Miller \& 341 Ostermeier, 2013). It remains unknown, however, whether the RNA by some means marks 342 the genome before entry into the ooplasm, at fertilisation, of some point after fertilisation.

343 Studies have shown significant differences in the levels of mRNA transcripts within 344 the testes of obese and lean mice (Ghanayem et al., 2010). However, the potential role of 345 sperm RNA, particularly in terms of functionality and a potential feature of fertilisation and 346 embryo development, remains a topic of some debate and represents a particular focus of 347 many research groups. 
Sperm DNA integrity in sub-fertile obese men

350

Numerous studies, carried out in both human and animal models, have identified a

relationship between obesity and a reduction in the DNA integrity of sperm, which would

thus have consequential implications upon fertilisation and embryonic development (Kort et

al., 2006; Kriegel et al., 2009; Chavarro et al., 2010; Bakos et al., 2011b, Fabriello et al.,

2012; LaVignera et al., 2012). In two different mouse models of obesity (high fat diet and leptin deficiency), increased BMI was successfully correlated to increased levels of sperm DNA fragmentation (Duale et al., 2014). An increased percentage of sperm with abnormally compacted chromatin, and an increased sperm DNA fragmentation index, was also detected in males with a BMI greater than $25 \mathrm{~kg} / \mathrm{m}^{2}$ (Kort et al., 2006; Lavignera et al., 2012). Conversely, a recent study by Eisenberg showed that increased BMI had no effect on the not be an appropriate index to use in such studies.

362

\section{Solutions to obesity related sub-fertility}

Developing treatments for infertility is challenging, as the nature of fertility is multifactorial. In addition to genetic or pathological infertility, there are many lifestyle factors which can affect reproductive health such as nutrition, weight, exercise, stress, environmental exposures, and drug use (Sharma et al., 2013). There are numerous lifestyle choices, which 368 could lead to obesity and its associated diseases and sub-fertility. One major challenge in 369 investigating how to treat sub-fertility associated with lifestyle factors is in considering how 370 lifestyle changes leading to sub-fertility are likely to influence both male and female 371 counterparts in a given couple. Therefore, if a male is obese and presenting with sub-fertility, 372 the lifestyle choices leading to his obesity are highly likely to affect his female partner also, 
373 and therefore it is more than likely that her weight could also be a contributory factor in the 374 couple's infertile status.

An individual's weight is often related to their eating habits and levels of activity. If one member of a couple is obese, there is a high likelihood that their partner may have a similar lifestyle and is also overweight or obese. Lifestyle changes though diet modifications and exercise can lead to gradual weight loss and thus help to overcome obesity and its associated preventable diseases. Several studies in obese males have reported that weight 380 loss through lifestyle changes resulted in increased SHBG and serum testosterone levels, as 381 well as reduced levels of insulin and leptin (Kaukua et al., 2003; Niskanen et al., 2004).

Since obesity appears to exert influence upon markers for male infertility, efforts have been undertaken to investigate whether measures taken to reverse the unhealthy consequences 384 of obesity can also reverse the deleterious effects upon fertility. When couples seek infertility 385 treatment and male factor infertility is diagnosed, most men present with a reduced ratio of 386 testosterone to oestrogen (Luboshitzky et al., 2002). Pharmacological interventions via 387 medication can be used to treat obesity by addressing weight loss via appetite suppressants, or 388 to treat the effects of obesity upon the male reproductive tract. Aromatase inhibitors can be 389 prescribed for males presenting with infertility problems, and who exhibit elevated estrogen 390 and reduced testosterone levels, in order to prevent the excessive conversion of testosterone 391 to estrogen (Elkhiat \& Fahmy, 2011; Schlegel, 2012). Studies have shown that the 392 administration of aromatase inhibitors is not only effective at restoring normal hormone 393 levels, but can also normalize spermatogenesis and semen parameters (Raman \& Schlegel, 394 2002; Zumoff et al., 2003; Roth et al., 2008). While these changes show some improvements 395 in markers for fertility, further investigation into the direct effects of such treatment and the 396 potential restoration of fertility are needed. 


\section{Conclusions}

399

Increased urbanization and industrialisation in the Western world has promoted a

400 sedentary lifestyle and unfavourable diet in the general population leading to an increased

401 incidence of obesity (Meldrum et al., 2012; Stefan et al., 2013). Studies have observed a

402 parallel decrease in male fertility potential over the past decades in regions where obesity is

403 prevalent (Swan et al., 2000). The diagnosis and treatment of reduced fertility in obese men

404 requires an insight into the underlying pathology, which has hormonal, mechanical,

405 molecular, and psychosocial aspects. The aetiology is multifactorial, with emerging evidence

406 showing that obese men having a greater risk of suffering from a dysregulated HPG axis and

407 thus endocrine profile, impaired spermatogenesis, and abnormal semen parameters.

408 Emerging evidence is showing that obesity negatively affects male reproductive potential, by

409 lowering the testosterone:oestrogen ratio, reducing sperm quality, altering the structure of

410 germ cells in the testes, and altering sperm RNA.

411 While several studies demonstrate short-term improvement in markers for male 412 fertility following weight loss via lifestyle modifications or surgical intervention, 413 unfortunately however, data pertaining to the long term success of such interventions are 414 lacking. Due to the complex interplay of factors contributing to subfertility associated with 415 obesity, there is a need for a multifaceted approach for further understanding and 416 development of treatments.

\section{Declaration of interests}

419 The authors report no declarations of interest. The authors alone are responsible for the 420 content and writing of the paper. 


\section{Acknowledgements}

423 LMD is funded by a Clarendon Scholarship from the University of Oxford.

424 
425

426 Figure legends

427 Figure 1 - Effects of obesity upon kisspeptin neurons is hypothesized as the central 428

429

430

431

432

433

434

435

436

437

438

439

440

441

442

443

pathway linking obesity to testosterone deficiency and subsequent male subfertility.

Excess adipose tissue results in increased circulating oestrogen, a chronic state of inflammation, and resistance to leptin and insulin. These effects upon the kisspeptin neuron result in reduced levels of kisspeptin production, consequently lowering GnRH, LH, and FSH release, ultimately reducing testosterone production and affecting spermatogenesis.

Figure 2 - The effects of excess visceral adipose tissue on the hypothalamic-pituitarygonadal axis. Increased amounts of adipose tissue increases the quantity and activity of aromatase which converts testosterone to estradiol in adipocytes. Estradiol inhibits the HPG axis via kisspeptin neurons, leading to decreased production of testosterone. Excess adipose causes insulin resistance, resulting in increased levels of insulin which decreases sexhormone-binding-globulin production in the liver, leading to increased levels of free oestrogen. Adipose tissue produces pro-inflammatory adipocytokines and leptin which effects the HPG through negative feedback. Leptin further inhibits the stimulation of gonadotropins on Leydig cells leading to decreased androgen production from the testes. 
444

\section{References}

446 Agarwal, A., Nandipati, K.C., Sharma, R.K., Zippe, C.D., \& Raina, R. (2006). Role of 447 oxidative stress in the pathophysiological mechanism of erectile dysfunction. Journal of 448 Andrology, 27, 335-347.

449 Agbaje, I.M., Rogers, D.A., McVicar, C.M., McClure, N., Atkinson, A.B., Mallidis, C., \& 450 Lewis, S.E.M. (2007). Insulin dependent diabetes mellitus: implications for male 451 reproductive function. Human Reproduction, 22, 1871-1877.

452 Aggerholm, A.S., Thulstrup, A.M., Toft, G., Ramlau-Hansen, C.H. \& Bonde, J.P. (2008). Is 453 overweight a risk factor for reduced semen quality and altered serum sex hormone profile? $454 \quad$ Fertility and Sterility, 90, 619-626.

455 Aitken, J.R., \& Baker, M.A. (2006). Oxidative stress, sperm survival and fertility control. 456 Molecular and Cellular Endocrinology, 250, 66-69.

457 Akingbemi, B.T. (2005). Oestrogen regulation of testicular function. Reproductive Biology 458 and Endocrinology 3, 1-13.

459 Anawalt, B.D. (2013). Approach to Male Infertility and Induction of Spermatogenesis. 460 Journal of Clinical Endocrinology and Metabolism, 98, 3532-3542.

461 Aziz, N., Saleh, R.A., Sharma, R.K., Lewis-Jones, I., Esfandiari, N., Thomas, A.J., \& 462 Agarwal, A. (2004). Novel association between sperm reactive oxygen species production, 463 sperm morphological defects, and the sperm deformity index. Fertility and Sterility, 81, 349464354. 
465 Bacon, C.G., Mittleman, M.A., Kawachi, I., Giovannucci. E., Glasser, D.B., \& Rimm, E.B. 466 (2003). Sexual Function in Men Older Than 50 Years of Age: Results from the Health 467 Professionals Follow-up Study. Annals of Internal Medicine 139, 161-168.

468 Bakos, H.W., Henshaw, R.C., Mitchell, M., \& Lane, M. (2011a). Paternal body mass index is 469 associated with decreased blastocyst development and reduced live birth rate following 470 assisted reproductive technology. Fertility and Sterility, 95, 1700-1704.

471 Bakos, H.W., Mitchell, M., Setchell, B.P., \& Lane, M. (2011b). The effect of paternal diet472 induced obesity on sperm function and fertilization in a mouse model. International Journal 473 of Andrology, 34, 402-410.

474 Barash, I.A., Cheung, C.C., Weigle, D.S., Ren, H., Kabigting, E.B., Kuijper, J.L., Clifton, 475 D.K., \& Steiner, R.A. (1996). Leptin is a metabolic signal to the reproductive system. 476 Endocrinology, 137, 3144-3147.

477 Barres, R. \& Zierath, J.R. (2011). DNA methylation in metabolic disorders. American 478 Journal of Clinical Nutrition, 93, 897S-900.

479 Bener, A., Al-Ansari, A.A., Zirie, M., \& Al-Hamaq, A.O. (2009). Is male fertility associated 480 with type 2 diabetes mellitus? International Urology and Nephrology, 41, 777-784.

481 Cabler, S., Agarwal, A., Flint, M., \& duPlessis, S.S. (2010). Obesity: modern man's fertility 482 nemesis. Asian Journal of Andrology, 12, 480-489.

483 Caprio, M., Isidori, A. M., Carta, A.R., Moretti, C., Dufau, M.L., \& Fabbri, A. (1999). 484 Expression of functional leptin receptors in rodent Leydig cells. Endocrinology, 139, 49394854947.

486 Chavarro, J. E., Toth, T. L., Wright, D. L., Meeker, J. D. \& Hauser, R. (2010). Body mass 487 index in relation to semen quality, sperm DNA integrity, and serum reproductive hormone 488 levels among men attending an infertility clinic. Fertility and Sterility, 93, 2222-2231. 
489 Colaci, D.S., Afeiche, M., Gaskins, A.J., Wright, D.L., Toth, T.L., Tanrikut, C., Hauser, R.. 490 \& Chavarro, J.E.. (2012). Men's body mass index in relation to embryo quality and clinical 491 outcomes in couples undergoing in vitro fertilization. Fertility and Sterility. 98:1193-9.e1.

492

Considine, R.V., Sinha, M.K., Heiman, M.L., Kriauciunas, A., Stephens, T.W., Nyce, M.R., 493 Ohannesian, J.P., Marco, C.C., McKee, L.J., Bauer, T.L., and Caro, J.F. (1996). Serum 494 immunoreactive-leptin concentrations in normal-weight and obese humans. New England 495 Journal of Medicine, 334, 292-295.

496 Dandona, P., Aljada, A., Chaudhuri, A., Mohanty, P., \& Garg, R. (2005). Metabolic 497 syndrome: a comprehensive perspective based on interactions between obesity, diabetes, and 498 inflammation. Circulation, 111, 1448-1454.

499 Daxinger, L., \& Whitelaw, E. (2012). Understanding transgenerational epigenetic inheritance 500 via the gametes in mammals. Nature Reviews Genetics, 13, 153-162.

501 DuPlessis, S.S., Cabler, S., McAlister, D.A., Sabanegh, E. \& Agarwal, A. (2010). The effect 502 of obesity on sperm disorders and male infertility. Nature Reviews Urology, 7, 153-161.

503 Eisenberg, M.L., Kim, S., Chen, Z., Sundaram, R., Schisterman, E.F., \& Buck Louise, G.M. 504 (2014). The relationship between male BMI and waist circumference on semen quality: data 505 from the LIFE study. Human Reproduction, 29, 193-200.

506 El Hajj, N., Zechner, U., Schneider, E. Tresch, A., Gromoll, J., Hahn, T., Schorsch, M., \& 507 Haaf, T. (2011). Methylation status of imprinted genes and repetitive elements in sperm DNA 508 from infertile males. Sexual Development, 5, 60-69.

509 Elkhiat, Y., \& Fahmy, I. (2011). Aromatase inhibitors in the treatment of male infertility. 510 Human Andrology. 1:35-38.

511 Esposito, K., Giugliano, F., Di Palo, C., Giugliano, G., Marfella, R., D’Andrea, F., 512 D’Armiento, M., \& Giugliano, D. (2004). Effect of lifestyle changes on erectile dysfunction 
513 in obese men: A randomized controlled trial. Journal of the American Medical Association, $514 \quad 291,2978-2984$.

515 Farthing, C.R., Ficz, G., Ng, R.K., Chan, C.F., Andrews, S., Dean, W., Hemberger, M., \& 516 Reik, W. (2008). Global mapping of DNA methylation in mouse promoters reveals 517 epigenetic reprogramming of pluripotency genes. PLOS Genetics, 4, e1000116.

518 Fariello, R.M., Pariz, J.R., Spaine, D.M., Cedenho, A.P., Bertolla, R.P., \& Fraietta, R. (2012). 519 Association between obesity and alteration of sperm DNA integrity and mitochondrial 520 activity. British Journal of Urology, 110, 63-867.

521 Fejes, I., Koloszár, S., Szöllosi, J., Závaczki, Z., \& Pál, A. (2005). Is semen quality affected 522 by male body fat distribution? Andrologia, 37, 155-159.

523 Fejes, I., Koloszar, S., Zavaczki, Z., Daru, J., Szollosi, J., \& Pal, A. (2006). Effect of body 524 weight on testosterone/estradiol ratio in oligozoospermic patients. Archives of Andrology, 52, $525 \quad 971-972$.

526 Finucane, M.M., Stevens, G.A., Cowan, M.J., Danaei, G., Lin, J.K., Paciorek, C.J., Singh, 527 G.M., Gutierrez, H.R., Lu, Y., Bahalim, A.N., Farzadfar, F., Riley, L.M., \& Ezzati, M. 528 (2011). National, regional, and global trends in body-mass index since 1980: systematic 529 analysis of health examination surveys and epidemiological studies with 960 country-years 530 and 9.1 million participants. The Lancet. 377:557-567.

531 Freedman, D.S. (2011). Obesity- Unites States, 1988-2008. Morbidity and Mortality Weekly 532 Report, 60, 73-77.

533 Fritz, M.A. \& Speroff, L. (2011). Clinical Gynecologic Endocrinology and Infertility. $8^{\text {th }}$ Ed. 534 (pp 1137, 1249). Philadelphia: Lippincott Williams \& Wilkins.

535 Fullston, T., Palmer, N.O., Owens, J.A., Mitchell, M., Bakos, H.W., \& Lane, M. (2012). 536 Diet-induced paternal obesity in the absence of diabetes diminishes the reproductive health of 537 two subsequent generations of mice. Human Reproduction, 27, 1391-1400. 
538 Gapp K., Jawald, A., Sarkies, P., Bohacek, J., Pelczar, P., Prados, J., Farinelli, L., Miska, E, 539 \& Mansuy, I.M. (2014). Implication of sperm RNAs in transgenerational inheritance of the 540 effects of early trauma in mice. Nature Neuroscience, 17, 667-669.

541 Gaucher, J., Reynoird, N., Montellier, E., Boussouar, F. Rousseaux, S., \& Khochbin, S. 542 (2010). From meiosis to post meiotic events: the secrets of histone disappearance. Federation 543 of European Biochemical Societies, 277, 599-604.

544 Ghanayem, B.I., Bai, R., Kissling, G.E., Travlos, G., \& Hoffler, U. (2010). Diet-induced 545 obesity in male mice is associated with reduced fertility and potentiation of acrylamide546 induced reproductive toxicity. Biology of Reproduction, 82, 96-104.

547 Hadjkacem, L.L., Hadjkacem, H., Bahloul, A., \& Ayadi, H. (2014). Relation between male 548 obesity and male infertility in a Tunisian population. Andrologia, Doi:10.1111/12257

549 Hajshafiha, M., Ghareaghaji, R., Salemi, S., Sadegh-Asadi, N., \& Sadeghi-Bazargani, H. 550 (2013). Association of body mass index with sme fertility markers among male partners of 551 infertile couples. International Journal of General Medicine, 6, 447-451.

552 Hammoud, A.O., Gibson, M., Peterson, C.M., Hamilton, B.D., \& Carrell, D.T. (2006). 553 Obesity and male reproductive potential. Journal of Andrology, 27, 619-626.

554 Hammoud, A.O., Gibson, M., Peterson, C.M., Meikle, A.W., \& Carrell, D. T. (2008). Impact 555 of male obesity on infertility: a critical review of the current literature. Fertility and Sterility, $55690,897-904$.

557 Hammoud, A.O., Meikle, A.W., Reis, L.O., Gibson, M., Peterson, M., \& Carrell, T. (2012). 558 Obesity and male infertility: a practical approach. Seminars in Reproductive Medicine, 30, $559 \quad 486-495$.

560 Handelsman, D.J., \& Swerdloff, R.S, (1985). Male gonadal dysfunction. Journal of Clinical 561 Endocrinology and Metabolism, 14, 89-124. 
562 Hinz, S., Rais-Bahrami, S., Kempkensteffen, C., Weiske, W.H., Miller, K. \& Magheli, A. 563 (2010). Effect of obesity on sex hormone levels, antisperm antibodies, and fertility after 564 vasectomy reversal. Urology, 76, 851-856.

565 Hofny, E.R., Ali, M.E., Abdel0Hafez, H.Z., Kamal, D., Mohamed, E.E., Abd ElAzeem, H.G., 566 \& Mostafa, T. (2009). Semen parameters and hormonal profile in obese fertile and infertile 567 males. Fertility and Sterility, 94, 581-584.

568 Hwang, K., Walters, R.C., \& Lipshultz, L.I. (2011). Contemporary concepts in the evaluation 569 and management of male infertility. Nature Reviews Urology, 8, 86-94.

570 Ishikawa, T., Fujioka, H., Ishimura, T., Takenaka, A. \& Fujisawa, M. (2007). Expression of 571 leptin and leptin receptor in the testis of fertile and infertile patients. Andrologia, 39, 22-27.

572 Isidori, A.M., Caprio, M., Strollo, F., Moretti, C., Frajese, G., Isidori, A., \& Fabbri, A. 573 (1999). Leptin and androgens in male obesity: evidence for leptin contribution to reduced 574 androgen levels. Journal of Clinical Endocrinology and Metabolism, 84, 3673-3680.

575 Jenkins, T., \& Carrell, D.T. (2012). Sperm specific chromatin modifications and their impact 576 on the paternal contribution to the embryo. Reproduction, 146, REP110450.

577 Jensen, T.K., Andersson, A.M., Jorgensen, N., Andersen, A.G., Carlsen, E., Petersen, J.H., \& 578 Skakkebaek, N.E. (2004). Body mass index in relation to semen quality and reproductive 579 hormonesamong 1,558 Danish men. Fertility and. Sterility, 82, 863-870.

580 Jones, T.H. (2010). Testosterone deficiency: a risk factor for cardiovascular disease? Trends 581 in Endocrinology and Metabolism, 21, 496-503.

582 Jope, T., Lammert, A., Kratzsch, J., Paash, U., \& Glander, H. (2003). Leptin and leptin 583 receptor in human seminal plasma and in human spermatozoa. International Journal of 584 Andrology, 26, 335-341. 
585 Jung, A., Eberl, M. \& Schill, W.B. (2001). Improvement of semen quality by nocturnal 586 scrotal cooling and moderate behavioural change to reduce genital heat stress in men with 587 oligoasthenoteratozoospermia. Reproduction, 121, 595-603.

588 Kasturi, S.S., Tannir, J., \& Brannigan, R.E. (2008). The metabolic syndrome and male 589 infertility. Journal of Andrology, 29, 251-259.

590 Kaukua, J., Pekkarinen, T., Sane, T., \& Mustajoki, P. (2003). Sex hormones and sexual 591 function in obese men losing weight. Obesity Research \& Clinical Practice.11, 689-694.

592 Keltz, J., Zapantis, A., Jindal, S.K., Lieman, H.J., Santoro, N., \& Polotsky, A.J. (2010). 593 Overweight men: clinical pregnancy after ART is decreased in IVF but not ICSI cycles. 594 Journal of Assisted Reproduction and Genetics, 27, 539-544.

595 Kerr, J.B., Millar, M., Maddocks, S., \& Sharpe, R.M. (1993a). Stage-dependent changes in 596 spermatogenesis and Sertoli cells in relation to the onset of spermatogenic failure following 597 withdrawal of testosterone. Anatomical Record, 235, 547-559.

598 Kerr, J.B., Savage, G.N., Millar, M., Sharpe, R.M. (1993b). Response of the seminiferous 599 epithelium of the rat testis to withdrawal of androgen: evidence for direct effect upon 600 intracellular spaces associated with Sertoli cell junctional complexes. Cell and Tissue 601 Research, 274, 153-161.

602 Kort, H.I., Massey, J.B., Elsner, C.W., Mitchell-Leef, D., Shapiro, D.B., Witt, M.A., \& 603 Roudebush, W.E. (2006). Impact of Body Mass Index Values on Sperm Quantity and 604 Quality. Journal of Andrology, 27, 450-452.

605 Kriegel, T.M., Heidrenreich, F., Kettner, K.,Pursche, T., Hoflack, B., Grunewald, S., 606 Poenicke, K., Glander, H.J., \& Paasch, U. (2009). Identification of diabetes- and obesity607 associated proteomic changes I nhuman spermatozoa by difference gel electrophoresis. 608 Reproductive Biomedicine Online, 19, 660-670. 
609 Kumanov, P., Nandipati, K., Tomova, A. \& Agarwal, A. (2006). Inhibin B is a better marker 610 of spermatogenesis than other hormones in the evaluation of male factor infertility. Fertility 611 and Sterility, 86, 332-338.

612 Lalancette, C., Platts, A.E., Johnson, G.D., Emery, B.R., Carrell, D.T., \& Krawetz, S.A. 613 (2009). Identification of human sperm transcripts as candidate markers of male fertility 614 Journal of Molecular Medicine, 87, 735-748.

615 La Vignera, S., Condorelli, R.A., Vicari, E. \& Calogero, A.E. (2012). Negative Effect of 616 Increased Body Weight on Sperm Conventional and Nonconventional Flow Cytometric 617 Sperm Parameters. Journal of Andrology, 33, 53-58.

618 Lei, S., Qipeng, Z., Binqiang, X., Xiaohong, J., Yutian, D., Chenyu, Z., \& Ke, Z. (2014). 619 Sustained high protein-tyrosine phosphatase 1B activity in the sperm of obese males impairs 620 the sperm acrosome reaction. Journal Biological Chemistry, 289, 8432-8441.

621 Li, L., Law, C., LoConte, R., Power, C. (2009). Intergenerational influences on childhood 622 body mass index: the effect of parental body mass index trajectories. American Journal of 623 Clinical Nutrition, 89, 551-557.

624 Luboshitzky, R., Kaplan-Zverling, M., Shen-Orr., Z., Nave, R. \& Here, P. (2002). Seminal 625 plasma androgen/oestrogen balance in infertile men. International Journal of Andrology. $626 \quad 25: 345-351$.

627 MacDonald, A., Herbison, G., Showell, M. \& Farquhar, C. (2010). The impact of body mass 628 index on semen parameters and reproductive hormones in human males: a systematic review 629 with meta-analysis. Human Reproduction Update, 16, 293-311.

630 Marques, C.J., Joao, M.P., Carvalho, F., Bieche, I., Barros, A., \& Sousa, M. (2011). DNA 631 methylation imprinting marks and DNA methyltransferase expression in human 632 spermatogenic cell stages. Epigenetics, 6, 1354-1361. 
633 Martini, A., Tissera, A., Estofan, D., Molina, R., Mangeaud, a., Cuneo, M., \& Ruiz, R.D. 634 (2010). Overweight and seminal quality: a study of 794 patients. Fertility and Sterility, 94, $635 \quad 1739-1743$.

636 Mascarenhas, M. N., Flaxman, S.R., Boerma, T., Vanderpoel, S., \& Stevens, G.A. 637 (2012). National, regional, and global trends in infertility prevalence since 1990: a 638 systematic analysis of 277 health surveys. PLoS Medicine, 9, e1001356

639 Meldrum, D.R., Gambone, J.C., Morris, MA., Esposito, K., Giugliano, D., \& Ignarro, .J. 640 (2012). Lifestyle and metabolic approaches to maximizing erectile and vascular health. 641 International Journal of Impotence Research, 24, 61-68.

642 Miller, D. \& Ostermeier, G.C. (2006). Towards a better understanding of RNA carriage by 643 ejaculate spermatozoa. Human Reproduction Update, 12, 757-767.

644 Minor, A., Chow, Z., \& Ma, S. (2011). Aberrant DNA methylation at imprinted genes in 645 testicular sperm retrieved from men with obstructive azoospermia and undergoing vasectomy 646 reversal. Reproduction, 141, 749-757.

647 Mitchell, M., Fullston, T., Palmer, N.O., Bakos, H.W., Owens, J.A., \& Lane, M. (2010). The 648 effect of paternal obesity in mice on reproductive and metabolic fitness of F1 male offspring. 649 Reproduction, Fertility and Development, 22, 21-21.

650 Nanassy, L., \& Carrell, D.T. (2011). Analysis of the methylation pattern of six gene 651 promoters in sperm of men with abnormal protamination. Asian Journal of Andrology, 13, $652 \quad 342-346$.

653 National Institutes of Health. (1998). Clinical guidelines on the identification, evaluation, and 654 treatment of overweight and obesity in adults - the evidence report. Obesity Research \& 655 Clinical Practice. 6(Suppl 2):51S-209S. 
656 Ng, S.F., Lin, R.C., Laybutt, D.R., Barress, R., Owens, J.A. \& Morris, M.J. (2010). Chronic

657 high-fat diet in fathers programs beta-cell dysfunction in female rat offspring. Nature, 467, $658963-966$.

659 Nguyen, R., Wilcox, A., Skjærven, R. \& Baird, D. (2007). Men's body mass index and 660 infertility. Human Reproduction, 22, 2488-2493.

661 Nicopoulou, S.C., Alexiou, M., Michalakis, K., Illias, I., Venaki, E., Koukkou, E., Mitios, G., 662 Billa, E., \& Adamopoulos, D.A. (2009). Body mass index vis-à-vis total sperm count in 663 attendees of a single andrology clinic. Fertility and Sterility, 92, 1016-1017.

664 Niskanen, L., Laasksonen, DE>, Punnonen, K., Mustajoki, P., Kaukua, J., Rissanen, A. 665 (2004). Changes in sex hormone-binding globulin and testosterone during weight loss and 666 weight maintenance in abdominally obese men with the metabolic syndrome. Diabetes, 667 Obesity, and Metabolism. 6, 208-215

668 Oliva, A., Spira, A., \& Multigner, L. (2001). Contribution of environmental factors to the risk 669 of male infertility. Human Reproduction, 16, 1768-1776.

670 Ooi, S.L., \& Henikoff, S. (2007). Germline histone dynamics and epigenetics. Current 671 Opinion in Cell Biology, 19, 257-265.

672 Ostermeier, G.C., Miller, D., Huntriss, J.D., Diamond, M.P., \& Krawetz, S.A. (2004). 673 Reproductive biology: delivering spermatozoan RNA to the oocyte. Nature, 429, 154.

674 Palmer, N.O., Fulston, T., Mitchell, M., Setchell, B.P., \& Lane, M. (2011). SIRT6 in mouse 675 spermatogenesis is modulated by diet-induced obesity. Reproduction, Fertility and 676 Development, 23, 929-939.

677 Palmer, N.O., Bakos, H.W., Fullston, T. \& Lane, M. (2012a). Impact of obesity on male 678 fertility, sperm function and molecular composition. Spermatogenesis, 2, 253-263. 
679 Palmer, N.O., Bakos, H.W., Owens, J.A., Setchell, B.P., \& Lane, M. (2012b). Diet and 680 exercise in an obese mouse fed a high-fat diet improve metabolic health and reverse 681 perturbed sperm function. American Journal of Physiology, Endocrinology and Metabolism, $682302, \mathrm{E} 768-780$.

683

Pasquali, R., Patton, L. \& Gambineri, A. (2007). Obesity and infertility. Current Opinions in 684 Endocrinology, Diabetes and Obesity, 14, 482-487.

685 Paul, C., Murray, A.A., Spears, N., \& Saunders, P.T. (2008a). A single, mild, transient scrotal 686 heat stress causes DNA damage, subfertility and impairs formation of blastocysts in mice. 687 Reproduction, 136, 73-84.

688 Paul, C., Melton, D.W., \& Saunders, P.T. (2008b). Do heat stress and deficits in DNA repair 689 pathways have a negative impact on male fertility? Molecular Human Reproduction, 14, 1-8. 690 Pauli, E.M., Legro, R.S., Demers, L.M., Kunselman, A.R., Dodson, W.C., \& Lee, P.A. 691 (2008). Diminished paternity and gonadal function with increasing obesity in men. Fertility 692 and Sterility, 90, 346-351.

693 Paradowska-Dogan, A., Fernandez, A., Bergmann, M., Kretzer, K., Mallidis, C., Vieweg, M., 694 Walisziewski, P., Zitzmann, M., Weidner, W., Steger, K., \& Kliesch, S. (2014). Protamins 695 mRNA ratio in stallion spermatozoa correlates with mare fecundity. Andrology, 2, 521-530.

696 Petersen GL, Schmidt L, Pinborg A, \& Kamper-Jørgensen M. (2013). The influence of 697 female and male body mass index on live births after assisted reproductive technology 698 treatment: a nationwide register-based cohort study. Fertility and Sterility. 99:1654-62

699 Raman, J.D. \& Schlegel, P.N. (2002). Aromatase inhibitors for male infertility. Journal of 700 Urology. 167, 624-629.

701 Ramlau-Hansen, C.H., Thulstrup, A.M., Nohr, E.A., Bonde, J.P., Sorensen, T.I., \& Olsen, J. 702 (2007). Subfecundity in overweight and obese couples. Human Reproduction, 22, 16347031637. 
704 Ramlau-Hansen, C.H., Hansen, M., Jensen, C.R., Olsen, J., Bonde, J.P., \& Thurstrup, A.M.

705 (2010). Semen quality and reproductive hormones according to birthweight and body mass

706 index in childhood and adult life: two decades of follow up. Fertility and Sterility. 94:610-

707618

708 Rao, P.M., Kelly, D.M., \& Jones, T.H. (2013). Testosterone and insulin resistance in the 709 metabolic syndrome and T2DM in men. Nature Reviews Endocrinology, 9, 479-493.

710 Robinson, D., Rock, J., \& Menkin, M.F. (1968). Control of human spermatogenesis by 711 induced changes of intrascrotal temperature. Journal of American Medical Association, 204, $712 \quad 290-297$.

713 Roth, M.Y., Amory, J.K., \& Page, S.T. (2008). Treatment of male infertility secondary to 714 morbid obesity. Nature Clinical Practice Endocrinology \& Metabolism. 4, 415-419

715 Ruwanpura, S.M., McLachlan, R.I., \& Maechem, S.J. (2010). Hormonal regulation of male 716 germ cell development. Journal of Endocrinology, 205, 117-131.

717 Reis, L.O. \& Dias, F.G.F. (2012). Male Fertility, Obesity, and Bariatric Surgery. 718 Reproductive Sciences, 19, 778-785.

719 Roth, M.Y., Amory, J.K., Page, S. (2008). Treatment of male infertility secondary to morbid 720 obesity. Nature Clinical Practice Endocrinology and Metabolism, 4, 415-419.

721 Schlegel, P.N. (2012). Aromatase inhibitors for male infertility. Fertility and Sterility. $72298: 1359-1362$.

723 Schliep, K.C., Mumford, S.L., Ahrens, K.A., Hotaling, J.M., Carrell, D.T., Link, M., Hinkle, 724 S.N., Kissell, K., Porucznik, C.A., \& Hammoud, A.O. (2015). Effect of male and female $\mathbf{7 2 5}$ body mass index on pregnancy and live birth success after in vitro fertilization. Fertility and 726 Sterility. Feb;103(2):388-95. 
727 Schneider, G., Kirschner, M. A., Berkowitz, R. \& Ertel, N. H. (1979). Increased Oestrogen

728 Production in Obese Men. Journal of Clinical Endocrinology \& Metabolism, 48, 633-638.

729 Sendler, E., Johnson, G.D., Mao, S., Goodrich, R.J., Diamon, M.P., Hauser, R. \& Krawetz, 730 S.A. (2013). Stability, delivery and functions of human sperm RNAs at fertilization. Nucleic 731 Acids Research, doi:10.1093/nar/gkt132

732 Sermondade, N., Faure, C., Fezeu, L., Shayeb, A.G., Bonde, J.P., Jensen, T.K., Van Wely, 733 M., Cao, J., Matini, A.C., Eskandar, M., Chavarro, J.E., Koloszar, S., Twigt, J.M., Ramlau734 Hansen, C.H., Borges, E., Lotti, F., Steegers-Thunissen, R.O., Zorn, B., Polotsky, A.J., 735 LaVignera, S., Eskenazi, B., Tremellen, K., Magnusdottir, E.V., Fejes, I., Hercberg, S., Levy, 736 R., \& Czernichow, S. (2013). BMI in relation to sperm count: an updated systematic review 737 and collaborative meta-analysis. Human Reproduction Update, 19, 221-231.

738 Sharma, R., Biedenharn, K.R., Fedor, J.M., \& Agarwal, A. (2013). Lifestyle factors and 739 reproductive health: taking control of your fertility. Reproductive Biology and 740 Endocrinology, 11, doi:10.1186/1477-7827-11-66.

741 Shiraishi, K., Takihara, H., \& Matsuyama, H. (2010). Elevated scrotal temperature, but not 742 varicocele grade, reflects testicular oxidative stress-mediated apoptosis. World Journal of 743 Urology, 28, 359-364.

744 Shulka, K.K., Chamial, S., Dwivedi, S., Misra, S., \& Sharma, P. (2014). Recent scenario of 745 obesity and male fertility. Andrology, 2, 809-818.

746 Stefan, N., Haring, H.U., Hu, F.B., \& Schulze, M.B. (2013). Metabolically healthy obesity: 747 epidemiology, mechanisms, and clinical implications. The Lancet Diabetes and 748 Endocrinology, 2, 152-162.

749 Svartberg, J., vonMuhlen, D., Sundsfjord, J., \& Jorde, R. (2004). Waist circumference and 750 testosterone levels in community dwelling men. The Tromso study. European Journal of 751 Epidemiology, 19, 657-663. 
752 Swan, S.H, Elkin, E.P., \& Fenster, L. (2000). The question of declining sperm density 753 revisited: an analysis of 101 studies published 1934-1996. Environmental Health Perspective. 754 108, 961-966.

755 Tchernof, A., Despres, J.P., Belanger, A., Dupont, A., Prudhomme, D., Morrjani, S., Lupien, 756 P.J., \& Labrie, F. (1995). Reduced testosterone and adrenal C19 steroid levels in obese men. 757 Metabolism, 44, 513-519.

758 Tunc, O., Bakos, H.W., \& Tremellen, K. (2011). Impact of body mass index on seminal 759 oxidative stress. Andrologia, 43, 121-128.

760 Tunc, O., \& Tremellen, K. (2011). Oxidative DNA damage impairs global sperm DNA 761 methylation in infertile men. Journal of Assisted Reproduction and Genetics, 26, 537-544.

762 Wang, P., Mariman, E., Renes, J., \& Keijer, J. (2008). The secretory function of adipocytes in 763 the physiologu of white adiose tissue. Journal of Cell Physiology, 216, 3-13.

764 Winters, S.J., Wang, C., Abderlrahaman, E., HAdeed, V., Dyky, M.A., \& Brufsky, A. (2006). 765 Inhibin-B Levels in Healthy Young Adult Men and Prepubertal Boys: Is Obesity the Cause 766 for the Contemporary Decline in Sperm Count Because of Fewer Sertoli Cells? Journal of 767 Andrology, 27, 560-564.

768 Youngson, N.A., \& Whitelaw, E. (2011). The effects of acquired paternal obesity on the next 769 generation. Asian Journal of Andrology, 13, 195-196.

770 Zorn, B., Vidmar, G., \& Meden-Vrtovec, H. (2003). Seminal reactive oxygen species as 771 predictors of fertilization, embryo quality and pregnancy rates after conventional in vitro 772 fertilization and intracytoplasmic spem injection. International Journal of Andrology, 26, $773 \quad 279-285$. 
1

2

3

4

5

6

7

8

9

10

11

12

13

14

15

16

17

18

19

20

21

22

23

24

25

26

27

28

29

30

31

32

33

34

35

36

37

38

39

40

41

42

43

44

45

46

47

48

49

50

51

52

53

54

55

56

57

58

59

60
774 Zumoff, B., Miller, L.K. \& Strain, G.W. (2003). Reversal of the hypogonadotropic

775 hypogonadism of obese men by administration of the aromatase inhibitor testolactone.

776 Metabolism. 52, 1126-1128.

777

778 
Dr Kevin Coward BSc (Hons) PhD FBiol FHEA

Nuffield Department of Obstetrics \& Gynaecology

Institute of Reproductive Sciences,

Oxford Business Park North,

Oxford. Oxfordshire.

OX4 2HW.

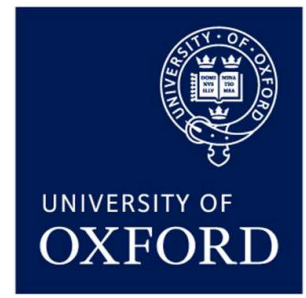

Tel: 01865782878

Email:kevin.coward@obs-gyn.ox.ac.uk

Website: www.obs-gyn.ox.ac.uk/research/kevin-coward/

$06 / 03 / 2015$

Dear Professor Leese,

\section{Re: THUF-2014-0158. Deleterious effects of obesity upon the hormonal and molecular mechanisms controlling spermatogenesis and male fertility. (Davidson et al.)}

Thank you for your letter dated $24^{\text {th }}$ February 2015 informing us that the above manuscript has been recommended for publication in Human Fertility following minor revision. We would like to thank the reviewers and the Editor for their pertinent and highly constructive comments. We have revised our manuscript in line with comments and requests. We attach a revised version of our manuscript. We believe that the revised manuscript is much improved and hope that the manuscript is now in a form that meets publication requirements.

We look forward to hearing from you in due course.

Yours sincerely,
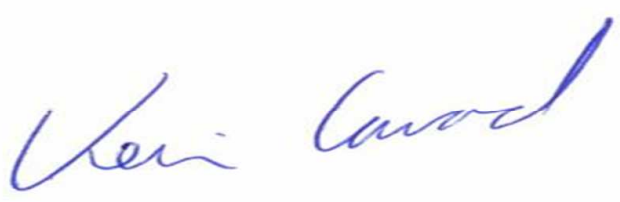

\section{Dr Kevin Coward}

Director, MSc in Clinical Embryology, Nuffield Department of Obstetrics \& Gynaecology, University of Oxford. Principal Investigator, Nuffield Department of Obstetrics \& Gynaecology, University of Oxford.

Fellow, Higher Education Academy. 


\section{Reviewer \#1}

Reviewer 1 found that the authors did an excellent job of thoroughly reviewing the male reproductive implications to obesity.

Comment 1: When mentioning the hypothesized importance of the $\mathrm{T}: \mathrm{E}$ ratio, the authors should mention the data on the use of aromatase inhibitors for male infertility.

Reply 1: We thank the reviewers for their constructive comment. The following text addition has been made to mention the use of aromatase inhibitors for male infertility and the new references have been added to the reference section.

\section{Start line 382}

"Since obesity appears to exert influence upon markers for male infertility, efforts have been undertaken to investigate whether measures taken to reverse the unhealthy consequences of obesity can also reverse the deleterious effects upon fertility. When couples seek infertility treatment and male factor infertility is diagnosed, most men present with a reduced ratio of testosterone to oestrogen (Luboshitzky et al., 2002). Pharmacological interventions via medication can be used to treat obesity by addressing weight loss via appetite suppressants, or to treat the effects of obesity upon the male reproductive tract. Aromatase inhibitors can be prescribed for males presenting with infertility problems, and who exhibit elevated estrogen and reduced testosterone levels, in order to prevent the excessive conversion of testosterone to estrogen (Elkhiat \& Fahmy, 2011; Schlegel, 2012). Studies have shown that the administration of aromatase inhibitors is not only effective at restoring normal hormone levels, but can also normalize spermatogenesis and semen parameters (Raman \& Schlegel, 2002; Zumoff et al., 2003; Roth et al., 2008). While these changes show some improvements in markers for fertility, further investigation into the direct effects of such treatment and the potential restoration of fertility are needed."

Comment 2: While passing mention is made in the conclusions, some discussion should be dedicated to the limited studies that explore the impact of weight loss on male fertility.

Reply 2: We thank the reviewers for their comment and suggestion to discuss the limited studies which explore the impact of weight loss on male fertility. We have added the below text to touch on this. (See also the reply to the Editor's comment regarding lifestyle impacts on obesity).

\section{Start line 375}

"An individual's weight is often related to their eating habits and levels of activity. If one member of a couple is obese, there is a high likelihood that their partner may have a similar lifestyle and is also overweight or obese. Lifestyle changes though diet modifications and exercise can lead to gradual weight loss and thus help to overcome obesity and its associated preventable diseases. Several studies in obese males have reported that weight loss through lifestyle changes resulted in increased SHBG and serum testosterone levels, as well as reduced levels of insulin and leptin (Kaukua et al., 2003; Niskanen et al., 2004)." 
Comment 3: The Lotti reference does not appear in the references section.

Reply 3: We thank the reviewers for pointing this out. In fact, this reference has now been changed to 'Swan et al (2000)' as this paper presents a more robust analysis of 101 studies.

Start line 407

"Studies have observed a parallel decrease in male fertility potential over the past decades in regions where obesity is prevalent (Swan et al., 2000)."

\section{Reviewer \#2}

Reviewer 2 found that the authors presented a strong and detailed review. The reviewer noted that the authors should check they are citing the relevant original articles. We have revised the text and references and made the corrections accordingly.

Comment 1: Line 24: "now affects around" change to "Infertility is estimated to affect one in seven...."

Reply 1: This text has been changed.

Start line 26

"Specifically, infertility is estimated to affect one in seven couples in the Western world, with male factor infertility contributing to approximately $40 \%$ of these cases, female factor infertility to $45 \%$, and the remaining proportion due to idiopathic causes (Fritz \& Speroff, 2011)."

Comment 2: Line 28: Back this up with a citation.

Reply 2: This text has now been updated with an in-text citation.

Start line 30

"Interestingly, there has been a steady decline in fertility rates over the past 50 years, which has occurred in parallel with an increasing rate of obesity (Hammoud et al., 2012)."

Comment 3: Line 31: Original article should be cited National Institutes of Health. Clinical guidelines on the identification, evaluation, and treatment of overweight and obesity in adults - the evidence report. Obes Res 1998;6(Suppl 2):51S-209S. (Also, it is the National Institutes of Health", please correct

Reply 3: We thank the reviewer for pointing out this error to us. The citation has now been changed and the original article added to the references section.

Start line 36

"According to the National Institutes of Health, individuals with a BMI between 25 and $29.9 \mathrm{~kg} / \mathrm{m}^{2}$ are classified as 'overweight', while those with a BMI greater or equal to $30 \mathrm{~kg} / \mathrm{m}^{2}$ are classified as 'obese' (National Institutes of Health, 1998).” 
Comment 4: Line 33-35: Authors start with rising infertility in Western world, then move to obesity epidemic in the US. But abstract addresses UK male obesity. Consistency and focus is important. If this article is meant to be generalizable to the "Western" world, I would recommend language that is consistent with this aim.

Reply 4: We thank the reviewer for pointing out this inconsistency with regards to the discussed regions of the obesity statistics in the US and UK and the infertility statistic in the Western world. In order to make the text generalizable, the text has now been changed in both the abstract and introduction to refer the worldwide prevalence of obesity and infertility rather than specific different countries. The new text is shown below, and these new references have been added to the reference section.

Start line 2

"Worldwide obesity rates have nearly doubled since 1980 and currently over $10 \%$ of the population is obese. In 2008, over 1.4 billion adults aged 20 and older were overweight; of these, over 200 million men and nearly 300 million women were obese."

Start line 25

"In 2010, 48.5 million couples globally were affected by infertility (Mascarenhas et al., 2012)."

Start line 36

"Between 1980 and 2008, worldwide prevalence of obesity nearly doubled, and more than $10 \%$ of the world's adult population is obese (Finucane et al., 2011)."

Comment 5: Line 42-44: Studies have actually been mixed with largest studies showing no adverse effects for male overweight in IVF couples. Should provide balanced and more up-todate evidence (see 1) Colaci DS, Afeiche M, Gaskins AJ, Wright DL, Toth TL, Tanrikut C, et al. Men's body mass index in relation to embryo quality and clinical outcomes in couples undergoing in vitro fertilization. Fertil Steril 2012;98:1193-9.e1. 2) Petersen GL, Schmidt L, Pinborg A, Kamper-Jørgensen M. The influence of female and male body mass index on live births after assisted reproductive technology treatment: a nationwide register-based cohort study. Fertil Steril 2013;99:1654-62 and 3) Schliep KC, Mumford SL, Ahrens KA, Hotaling JM, Carrell DT, Link M, et al. Effect of male and female body mass index on pregnancy and live birth success after in vitro fertilization. Fertil Steril. 2015Feb;103(2):388-95.

Also, it is important when giving a balanced presentation to talk about the strengths and weaknesses of studies (e.g., how many of the studies that the authors cite take into consideration the important element of confounding by maternal BMI?).

Reply 5: We thank the reviewer for their comment pointing out that larger recent studies have shown no adverse effects for overweight males in IVF couples, for providing associated references, as well as pointing out the importance of maternal BMI as a confounding variable. The new references have been added to the reference section. The following text has been added to the introduction and body of the article to discuss the recommended articles, and is further addressed in the reply to comment 9. 


\begin{abstract}
Start line 43
"While current data remains highly conflicting, mounting evidence indicates that male obesity is associated with an increased time to conception, reduced pregnancy rates, and an increase in pregnancy loss in couples undergoing assisted reproductive techniques (ART) (Nguyen et al., 2007; Ramlau-Hansen et al., 2007; Hinz et al., 2010; Keltz et al., 2010; Bakos et al., 2011a)."
\end{abstract}

\begin{abstract}
Start line 199
"Another important concern to take into account when analysing the effects of male obesity upon semen abnormalities is the potential confounding effect of maternal obesity and whether this leads to semen abnormalities in male offspring. It was hypothesized in 2007 that maternal obesity could have a programming effect upon testicular development in foetal life (Ramlau-Hansen et al., 2007). The authors observed that the sons of mothers who were overweight or obese during pregnancy were more likely to be overweight at birth and exhibit a high BMI in adulthood compared to the sons of normal weighted mothers. It was also suggested that higher free oestrogen levels in mothers (and hence the foetus) could interfere with normal testicular development and future fertility (RamlauHansen et al., 2007). More recently, the same group reported that there was no obvious relationship between high birth weight/prepubertal body fat and semen quality in young adult life, suggesting that the effects of maternal obesity during pregnancy are unlikely to have an effect upon semen quality and subsequent fertility (Ramlau-Hansen et al., 2010)."
\end{abstract}

\title{
Start line 244
}

"It should be kept in mind that in many of these studies, the confounding effect of maternal obesity is often not taken into account when associating outcomes to the incidence of male obesity. A recent study reported that weight status (overweight or obese) does not influence fecundity in couples undergoing infertility treatment. In fact, Schliep et al. (2015) investigated the effects of both male and female body-mass index on pregnancy and birth rates following in vitro fertilisation, and after adjusting for partner BMI, found no significant differences between fertilisation rate, embryo score, pregnancy, or live birth rate compared with normal weight controls."

Comment 6: Line 102: This should be clarified to couples seeking infertility treatment whereby male factor is diagnosed. Also, please cite original source of article, Tsai article has a different objective then assessment presented in this sentence. Cannot even find mention of "infertility treatment" in the article, is this even the right citation?

Reply 6: We thank the reviewers for their comment. The text has been clarified to indicate couples where male factor infertility is diagnosed, and the reference has been fixed.

\section{Start line 385}

"When couples seek infertility treatment and male factor infertility is diagnosed, most men present with a reduced ratio of testosterone to oestrogen (Luboshitzky et al., 2002).” 
Comment 7: Line 120 delete "upon"

Reply 7: Done

Comment 8: Lines 165-168: Re: "Interestingly however, one study reported a significant association between BMI and semen quality even following an adjustment for reproductive hormones, suggesting that altered hormone profiles in obese men may not be solely responsible for infertility problems (Qin et al., 2007)." This study does not seem to support the statement, since Qin et al found that only underweight men had reduced semen quality after adjusting for hormone levels. In contrast to what the authors are advocating, Qin et al actually found that "Being underweight may be a risk factor for low sperm concentration (OR: 4.68, 95\% confidence intervals [CI]: 2.01-10.91). Otherwise, being overweight may be a protected factor for low sperm concentration (OR: 0.25 ; 95\% CI: $0.08-0.83$ ) and low total sperm count (OR: 0.37, 95\% CI: 0.15-0.87)."

Reply 8: We thank the reviewers for their comment and in pointing out that since the reduced semen quality was only found in underweight men it therefore cannot be extrapolated to make conclusions about the effects of hormone profiles in obese men and corresponding fertility status. This text has been removed.

Comment 9: Lines 212-213: Again, authors are leaving out important recent studies with among much larger studies. This is concerning in that the authors of a review article such as this should have up to date information. See comment re: lines 42-44 for studies that should be added.

Reply 9: We have taken the reviewers suggestions and added information from the recommended more recent and larger study. The new reference has been added to the reference section. The following text has been added (as well as the text in response to comment 5).

Start line 222

"Interestingly, one study noted that fertilisation rate was higher among obese men than men of normal weight for conventional IVF cycles, and that there were no significant associations between male BMI and poor quality embryos or cleavage rate (Colaci et al., 2012). However, this same study showed that the odds of live birth in couples with obese male partners undergoing ICSI was $84 \%$ lower than men with normal BMI and concluded there is a possible deleterious effect of male obesity on the odds of having a live birth rate (Colaci et al, 2012)." 
Comment 10: Line 214: But if male BMI affects whether a couple is treated with ICSI or not, then adjusting for ICSI may lead to over adjustment bias (see Schliep et al 2014 for an explanation as to why stratifying on ICSI may not be appropriate).

Reply 10: We thank the reviewers for their comment and recommendation to see Schliep et al for a good explanation against stratifying results on ICSI. The text has been amended to point out the over adjustment bias that may occur when stratifying data by ICSI, and the reference has been added to the reference section.

Start line 228

"It should be noted however, that if male BMI influences whether patients are treated with ICSI, stratifying data by ICSI may lead to over adjustment bias and thus confound the observed outcomes (Schliep et al., 2015). Conversely, other studies report that for obese patients, rates of fertilisation (Keltz et al., 2010) and live birth rates (Peterson, et al. 2013) are reduced following in vitro fertilisation (IVF) but not following ICSI, suggesting impairment in sperm binding."

Comment 11: Lines 250-266: But other studies the authors bring up (e.g., see Qin et al) discuss poor semen quality of underweight males. Do the authors of these cited studies look at trans-generational effects of underweight males? Do these studies control for maternal BMI?

Reply 11: We thank the reviewers for their questions. The text in this article regarding the Qin et al. study has been removed. However in response to the reviewer's question, the authors did not look at the trans-generational effects of underweight males and did not control for maternal BMI. The following text has been added to the body of the text to indicate that in general, studies should also investigate the effects of underweight males on transgenerational effects.

Start line 325

"Furthermore, studies looking into the trans-generational effects of underweight males should also be undertaken to further investigate the trans-generational effects of weight on DNA integrity and sperm RNA levels."

Comment 12: Lines 265-266 advocacy for potentially not treating obese males with ART seems ethically concerning given that this is novel research and full assessment has not been undertaken. And particularly when in earlier and later paragraphs you highlight that BMI might not be an appropriate marker for adiposity. 
Reply 12: We thank the reviewers for their comments showing that the initial sentence could be misconstrued and misinterpreted as the authors advocating for not treating obese males with ART. The sentence has been replaced with the following text in red to avoid this potential misunderstanding:

Start line 287

“A hypothesis known as 'trans-generational epigenetic inheritance' now purports that molecular changes resulting from impaired spermatogenesis due to obesity, such as changes to DNA methylation, histone acetylation or non-coding RNA levels in sperm, are transmitted to the embryo and consequently affect subsequent development (Youngson \& Whitelaw, 2011; Daxinger et al., 2012; Palmer et al., 2012). This represents an interesting area which needs to be investigated further and could help to develop and improve infertility treatments."

\section{Comments from the Editor, Professor Henry Leese}

The Editor found that the authors provided a well presented review on an interesting topic.

Comment: I would like the authours however to comment more on the multifactorial nature of infertility. In particular the lifestyle choices that lead to an obese male can also effect the female partner. This will lead to the question of whose obesity is impacting lack of fertility more!

Reply: We thank the editor for his useful comment and raising the interesting point of discussion regarding subfertility in couples where both partners could be obese.

Start line 364

"Developing treatments for infertility is challenging, as the nature of fertility is multifactorial. In addition to genetic or pathological infertility, there are many lifestyle factors which can affect reproductive health such as nutrition, weight, exercise, stress, environmental exposures, and drug use (Sharma et al., 2013). There are numerous lifestyle choices, which could lead to obesity and its associated diseases and sub-fertility. One major challenge in investigating how to treat sub-fertility associated with lifestyle factors is in considering how lifestyle changes leading to sub-fertility are likely to influence both male and female counterparts in a given couple. Therefore, if a male is obese and presenting with sub-fertility, the lifestyle choices leading to his obesity are highly likely to affect his female partner also, and therefore it is more than likely that her weight could also be a contributory factor in the couple's infertile status." 


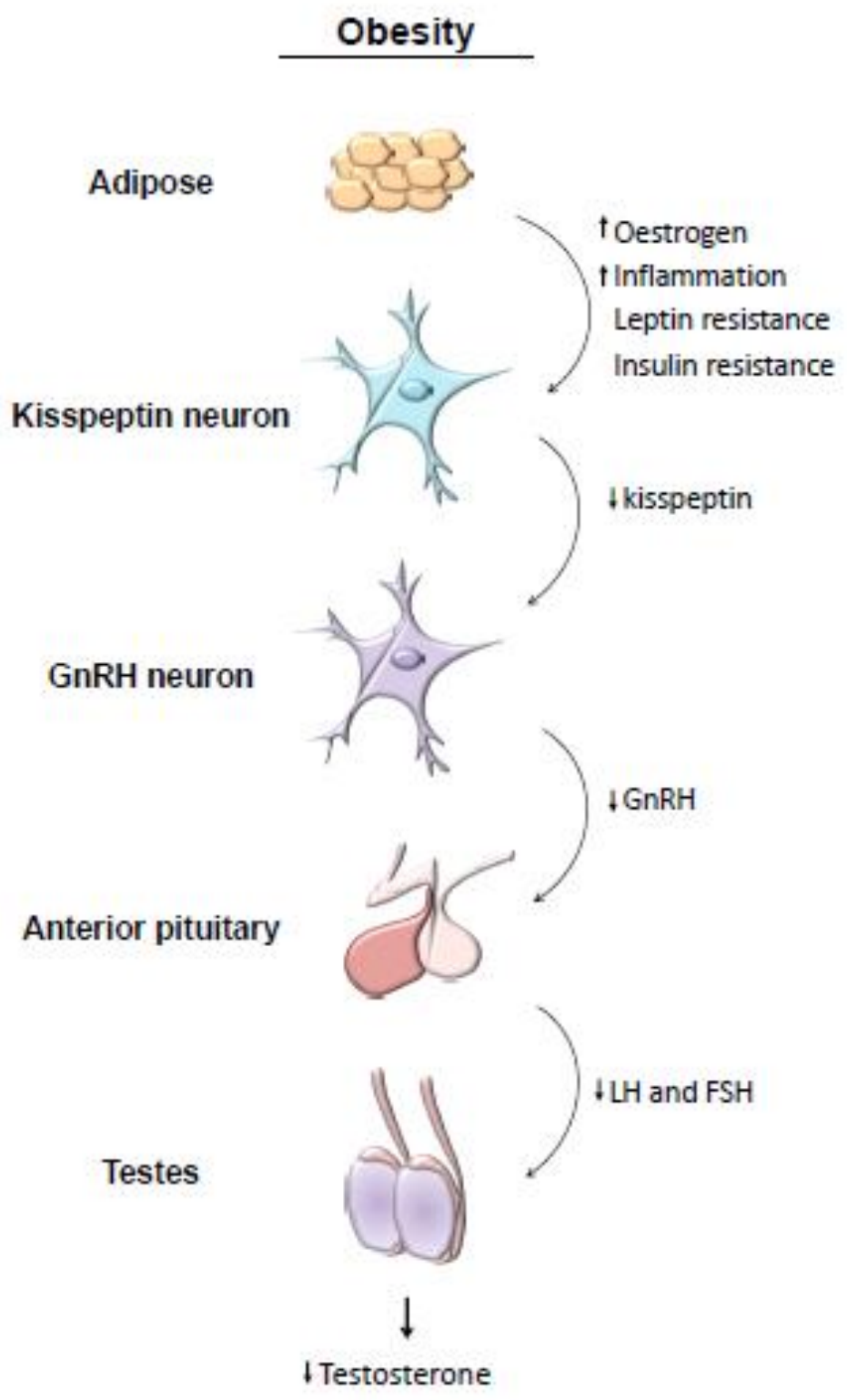

Figure 1 


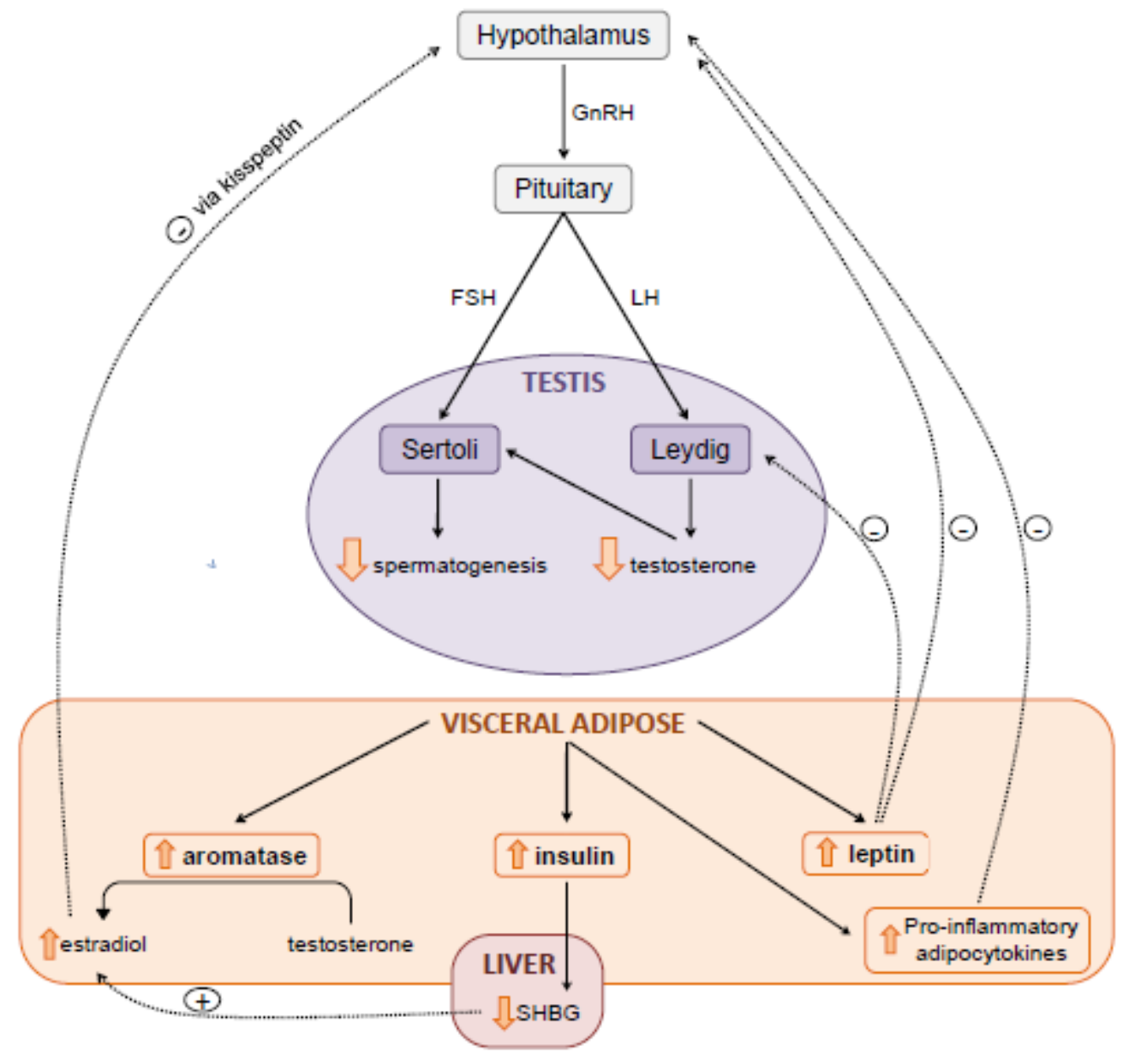

Figure 2 


\section{AUTHOR DECLARATION}

We wish to confirm that there are no known conflicts of interest associated with this publication and there has been no significant financial support for this work that could have influenced its outcome.

We confirm that the manuscript has been read and approved by all named authors and that there are no other persons who satisfied the criteria for authorship but are not listed. We further confirm that the order of authors listed in the manuscript has been approved by all of us.

We confirm that we have given due consideration to the protection of intellectual property associated with this work and that there are no impediments to publication, including the timing of publication, with respect to intellectual property. In so doing we confirm that we have followed the regulations of our institutions concerning intellectual property.

We further confirm that any aspect of the work covered in this manuscript that has involved either experimental animals or human patients has been conducted with the ethical approval of all relevant bodies and that such approvals are acknowledged within the manuscript

We understand that the Corresponding Author is the sole contact for the Editorial process (including Editorial Manager and direct communications with the office). He is responsible for communicating with the other authors about progress, submissions of revisions and final approval of proofs. We confirm that we have provided a current, correct email address which is accessible by the Corresponding Author and which has been configured to accept email from:

Dr. Kevin Coward: kevin.coward@obs-gyn.ox.ac.uk

Signed by all authors as follows:

Authors:

1) Miss. Lien M Davidson

2) Miss. Kate Millar

3) Mrs. Celine Jones

4) Dr. Muhammad Fatum

5) Dr. Kevin Coward
Date:
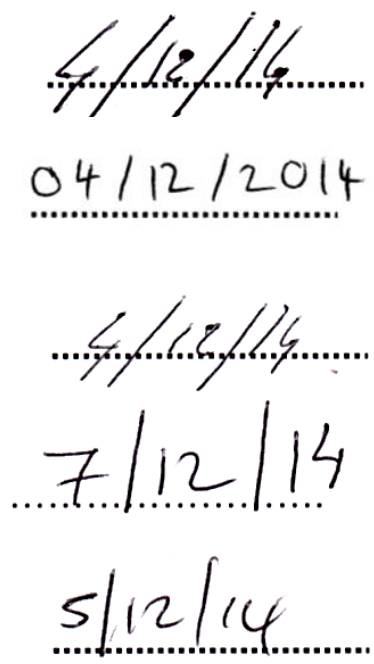

Signature:
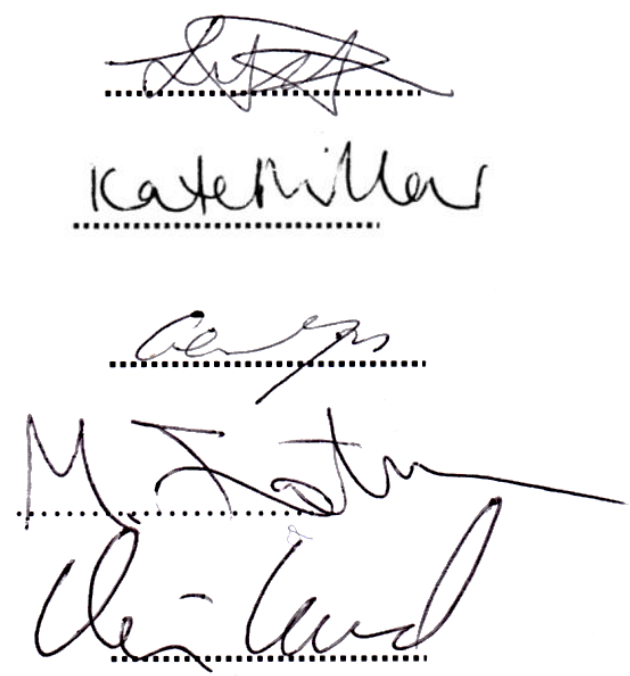